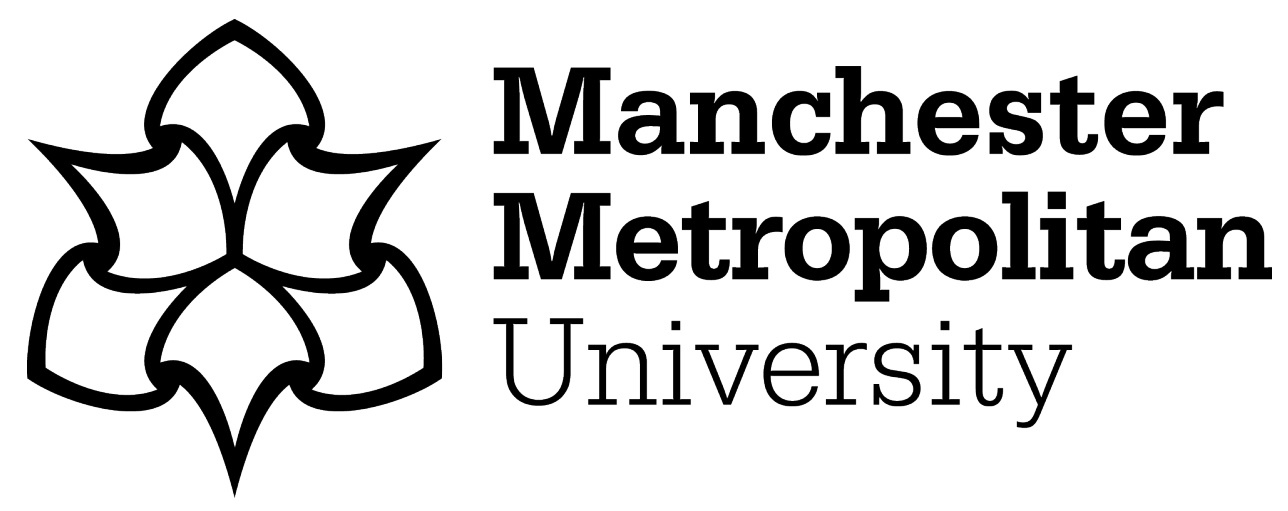

Tan, KS ORCID logoORCID: https://orcid.org/0000-0002-4491-7166 (2018) An exploration of running as metaphor, methodology, material through the RUN! RUN! RUN! Biennale \#r3fest 2016. Sport in Society, 22 (5). pp. 829845. ISSN 1743-0437

Downloaded from: https://e-space.mmu.ac.uk/624382/

Version: Accepted Version

Publisher: Taylor \& Francis (Routledge)

DOI: https://doi.org/10.1080/17430437.2018.1430488

Please cite the published version 


\title{
An exploration of running as metaphor, methodology, material through the RUN! RUN! RUN! Biennale \#r3fest 2016
}

\author{
Kai Syng Tan
}

Social, Genetic and Developmental Psychiatry (SGDP), Institute of Psychiatry, Psychology and Neuroscience, King's College London

King's College London, MRC SGDP 16 De Crespigny Park, London, SE5 8AF

Email: kai@kaisyngtan.com Twitter: @kaisyngtan

Dr Kai Syng Tan FRSA SFHEA is an artist and curator. Through installation, performance, film and text, she explores the body and mind in (com)motion. Since 2009, the focus has been on running as an arts and humanities discourse, and her role has been described by artist Professor Gregg Whelan as 'instrumental in the UK and lots of other contexts in pulling together all sorts of writers, artists, academics and performance-makers to come together and to start to form what might become to be called "Running Studies"'. The first run of her curated RUN! RUN! RUN! Biennale was praised by the Guardian for its 'positive atmosphere' (2014). Before she ran, she swam, hopped, skipped and drowned. The results have been shared at Documenta, Royal Geographical Society, Biennale of Sydney, MOMA, BBC Radio 3 Free Thinking, and a few are collected by the Museum of London and Fukuoka Art Museum. Currently an artist-inresidence at King's College London, Visiting Fellow at University College London and Director of RUN! RUN! RUN! International Body for Research, Kai completed her PhD at the Slade School of Fine Art, University College London. 


\section{An exploration of running as metaphor, methodology, material through the RUN! RUN! RUN! Biennale \#r3fest 2016}

This paper runs through the RUN! RUN! RUN! Biennale's origins, curatorial framework, and its potential future impact. Also known as \#r3fest, the Biennale is an interdisciplinary programme exploring running as an arts and humanities discourse. Exploring running as creative material, metaphor and methodology, the 2016 edition threw a spotlight on live art, drawings, films and activities by practitioners in the arts, academia and NGOs which have hitherto been underrepresented in dominant discourses in the emerging field of 'Running Studies'. The paper raises philosophical questions about synergies between arts and sport. Examples of practice across visual and performance art locates RUN! RUN! RUN! and the paper in the area of curating, suggesting a new way of considering how arts and sports can be organised, considered and presented. Its aim is to help to widen the discourse, invite curators, artists and academics to consider, curate and create yet other experiments that activate running as creative material, metaphor and methodology, and challenge existing assumptions in the arts about sport.

Keywords: running, productive antagonism, collage, art, visual art, drawing, performance, practice-led research, practice-based research, interdisciplinary, feminist, innovation. 


\section{Rundown}

Stripped to its barest essentials the act of running is remarkable for its stunning simplicity. The movement of putting one foot in front of the other. And yet such definition betrays its nuanced complexity, multiplicity of meanings and inbuilt contradictions. As John Bale opines, an "understanding of running cannot be achieved by simply looking at runners". Of equal consideration is the socio-cultural context in which running occurs. Thus how might one critically interpret running as a political act of defiance in the hands (or rather feet) of women and girls in a conflict-affected region of Afghanistan, alongside privileged (predominantly male) Western fitness tourists testing their resilience, endurance and strength against the exotic extremities of the Saharan landscape in the Marathon des Sables? What can be learned or revealed from mobilising running to comprehend the experiences of refugees fleeing persecution and torture when juxtaposed with aesthetic displays of suffering in endurance sports through documentation in contemporary art? This is the intentionally jarring backdrop to the opening leg of the triptych Run! Run! Run! Biennale 2016, which as curator Kai Syng Tan alludes is the darker 'difficult second album" — David Hindley, on RUN! RUN! RUN! Biennale 2016 Leeds Leg (2016)

Working in collaboration with two other artists Annie Grove-White and Carali McCall, I curated the RUN! RUN! RUN! Biennale \#r3fest in 2016. The interdisciplinary programme explored the ways in which running could be activated as a creative material, metaphor and methodology to think through critical issues related to the body, gender, ageing, the city and borders. Featuring 27 colleagues from 16 academic, artistic and charitable institutions, it consisted of three events that took place over three days across three sites. Focusing on running as a tool to consider the limitations and possibilities of the body, the 'Cardiff Leg' was an evening of live art performances at the National Indoors Athletics Centre in Cardiff, Wales. Zooming out, the 'London Leg' investigated how this running body relates with the city, through a film screening and running tour that took place at University College London and the King's Cross vicinity. Zooming out further, the 'Leeds Leg' examined the ways we run — physically and/or metaphorically — across geopolitical and disciplinary borders, through a seminar at held at Leeds College of Art (Figure I).

Following in the footsteps of the inaugural \#r3fest, the 2016 run aimed to create a place where the usual norms of disciplinary practice were temporarily suspended, 
where creative collisions and 'productive antagonisms' occur (Latham and Tan 2016). This collage-like approach of mixing disparate disciplines together to engineer exchanges is itself informed by the exuberance of running (Tan 2014a). As David Hindley, a runner and Sports Education academic at Nottingham Trent University points out, \#r3fest provoked 'conversations across different disciplines, in the process stimulating new research directions and creative collaborations to add to our existing understanding of, and fascination with, running' (2016). The 2016 programme had an additional agenda. It was to highlight activities - including those by colleagues from outside of the arts and academia - that have hitherto been underrepresented in dominant discourses in the emerging field of 'Running Studies'.

$$
<<\text { Figure } 1 \text { here }>>
$$

Figure 1: Flyer for RUN! RUN! RUN! Biennale. (Tan 2016d)

The aim of \#r3fest, and this paper, is not to prescribe a magic formula for how the arts and running could collaborate. Instead, its goal is to widen the conversation, call on the curators, artists and academics to consider, curate and create yet other innovative entanglements of the arts and running (and, by extrapolation, sport in general), and along the way interrogate and (re-)energise some of the existing conventions and assumptions in the art world.

\section{Points of departure}

But before we go into the detail of a few of these innovative experiments, I wish to address: Why running, how can we unpack it to consider its physical and poetic processes and its possibilities as material, metaphor and methodology? Why was \#r3fest set up, and why the interdisciplinary, 'running' approach? What is 'Running Studies', and why the need to showcase overlooked examples in the 2016 run?

\section{Running: not run of the mill}

An observation by Matti Tainio, of Aalto University's School of Arts Design and Architecture, could be useful to get us started. The artist and runner considers \#r3fest an attempt to 'build connections between different running practices' with academic and 
artistic disciplines (2016). It is an 'important step in a path' that helps us to understand the 'different meanings of running' beyond the concept of sport.

Running has indeed a rich repertoire of meanings and registers. Since the 1970's, the world has bene experiencing what British runner Sir Roger Bannister calls a 'running boom' (cited in Newsholme and Leech 1983, vi). In this 'nation of runners' (Wray 2014), nearly 40,000 runners participate in the annual London Marathon, which has seen 1,003,473 finishers since its inception in 1981 (Virgin Money London Marathon 2017). Worldwide, a marathon held daily (Marathon Guide 2012), and Palestine held its first - aptly named Right To Movement - in 2013 (Palestine Marathon 2013).

Yet, running is not just about marathons, nor is it a recent development. As toddlers, as soon as we could walk, we ran, and ran about — until our parents and teachers reprimanded 'Walk! Don't run!'. In fact, our ancestors have run for 2 million years - which could be an explanation behind why running as a fitness practice appeals to so many people today. In the days before weapons were invented, the Homo erectus ran for up to 6 hours across 20 miles (Liebenberg 2008) - just short of the distance of a full marathon - to hunt for food in a practice known as persistence hunting. After all, human beings are 'born to run' long distances (Bramble and Lieberman 2004), endowed as we are with unique physical attributes 'tailor-made for running' (Bramble and Lieberman, cited in Chen 2006). Nonetheless, as any endurance runner will attest, the physical is only one part of the equation. It was our ancestors' persistence and 'ability to dream far ahead' (Heinrich 2002, 177) that empowered them to take the first steps to chase the antelope in the first place.

The running-dreaming correlation allows us to direct this discussion towards the arts - and this is where we find plenty of evidence about how running have been a resource for writers, artists and thinkers in direct and indirect ways. For American novelist and runner Joyce Carol Oates we possess 'peculiar powers of locomotion' when we dream, which are:

'[...] atavistic remnants, the hallucinatory memory of a distant ancestor for whom the physical being, charged with adrenaline in emergency situations, was indistinguishable from the spiritual or intellectual. In running, "spirit" seems to pervade the body; as musicians experience the uncanny phenomenon of tissue memory in their fingertips, so the runner seems to experience in feet, lungs, quickened heartbeat, an extension of the 
imagining self' (1999).

For Oates, this ineffable energy felt in the toes, lungs and quickened heartbeat of the runner can even be the fuel that is 'nourishing to the imagination'. Her novel Do With Me What You Will was composed while she ran at Hyde Park, London. Hyde Park was conducive for Jeremy Bentham too, for, that was where he went running before dinner. Fitting his reputation as a neologism-loving eccentric, the philosopher (17481832) referred to these as referred to as his 'preprandial circumgyrations' (Wheatley 2015 , 4). His association with utilitarianism is undisputed, but it is a little-known fact that Bentham was a runner before running was what we call a 'fitness practice' (Latham 2015) today. Perhaps like the novelist Haruki Murakami, and the contemporary runner, Bentham could have found running a useful means to declutter his thoughts. For British painter Jo Volley (born 1953), her site of action is Hampstead Heath, where she picks up oak apples during her runs, from which she extracts ink to create her paintings (2014).

Apart from playing an important role in their creative processes, running has also been activated by arts practitioners as material or medium in their work. An example is Turner Prize winner Martin Creed's 2008 Work No. 850, in which runners sprinted for 30 seconds each time within the hallowed halls of the Tate, which are expressions of 'being alive' (2008). Then, there are works in which running is the subject matter. Who can forget the angry young man Colin in the short story The Loneliness of the Long Distance Runner (Sillitoe 2010), or the feisty Lola who ran and transformed her fate in the cult film Run Lola Run (Tykwer 1999)?

\section{Upping the speed and upping the game in art and academia}

The list goes on. Clearly, the connections between different running practices with academic and artistic disciplines are multiple, complex and exciting. There are rich possibilities of running as a creative material, metaphor and methodology. Why, then, has the running boom not (yet) been picked up on or reflected in the academic arena? As geographer John Bale states in his book entitled Running Cultures, although running is 'one of the worlds most widely practiced sports and recreations', it has tended to 'elude serious study outside of the natural sciences' (2004). The art world fares no better. Artist-curator Gregg Whelan points out that artists are 'beginning to exploit 
sport's ability to produce meaningful narratives from physical action' (2017), but why aren't more of them jumping up and down and capitalising on running in their work? After all, artists have always been opportunistic and co-opted materials from other worlds into their work — think bronze, spray paint, newspaper cuttings, data. A few Alister artists have 'outed' themselves as exercise and sports enthusiasts. This includes kayaking for Chris Ofili (Searle 2017) and swimming 40 lengths of backstrokes in a purpose-built $16 \mathrm{~m}$ underground Victorian-tiled single-lane pool in Shoreditch for Tracey Emin (Godwin 2005; Hind 2014). However, as self-titled 'transvestite potter' and cycling enthusiast Grayson Perry argues, there is a 'popular idea that artists are not supposed to be sporty' (2015). For many, the myth of the 'creative genius' doused in self-destruction and melancholy is more attractive than the one drenched in sweat in a pair of running shorts. Drugs, alcohol and pills are a sexier fuel than carbs, gels and endocannabinoids, which are cannabis-like hormones manufactured by the brains ('endo' means from within) from vigorous exercise, in particular running (Dietrich and McDaniel 2004). Talk about running in the same breath as art, and the cultural elite run a mile. That may be why Turner Prize winner Keith Tyson, has been alleged to be a closet runner even though he has been spotted running everyday to train for a triathlon. His eye-witness is his neighbour, Jonathan Buckley, himself a novelist - and runner (Tan 2014a, 188). Art and architectural departments enshrine the cultural tradition of walking in their curriculum (Glasgow School of Art 2011; Bartlett School of Architecture 2016). If this is could be called 'Walking Studies' (think Walter Benjamin, Richard Long, William Wordsworth, Rebecca Solnit), is it not time to up the speed, and up the game, and introduce what Whelan has termed 'Running Studies' (cited in Tan 2015 ) into the academy, and give the walking canon a good run for its money?

\section{Stepping in to fill the gaps: the inaugural RUN! RUN! RUN!}

To help to address the gap, I founded the RUN! RUN! RUN! International Festival of Running in 2014 (Figure 2). Also known as the \#r3fest, this was a hybrid programme examining running as an arts and humanities discourse. I approached Alan Latham, a geographer from University College London, to be Co-Director, and artist Jo Volley as co-host. Funded by University College London and the Arts and Humanities Research Council, the one-day event took place at the Slade Research Centre, and was attended 
by 50 artists, academics and community leaders from 30 institutions and including the Universities of Harvard and Oxford, Goodgym and the Sri Chimnoy Centre (Tan 2014b). Disciplines were jumbled up to generate lively, productive antagonisms, practice was mixed with research, and cultural and academic hierarchies and boundaries irritated. The usual presentations aside, there were quick-fire, 8-minute speaking slots that we timed with a stopwatch. Object-based learning activities were also programmed in, as paleo-anthropologists brought samples illustrating anatomical parts of the human runner for participants to explore. Academic posters, such as one on the biomechanics of running, were juxtaposed with commissioned artworks, such as Volley's drawing of a map of her run at Hampstead Heath (Figure 3). A meditation session was deliberately scheduled to take place at the same time as a lecture on running injury by a medic, 'forcing' the festival goers to choose between spiritualism and science. Senior academics intermingled with unknowns (we took a chance with two female performers, including a 23-year-old undergraduate).

$<<$ Figure 2 here $>>$

Figure 2: An overview of RUN! RUN! RUN! International Festival of Running. (Latham and Tan 2016)

While I have investigated the body and mind in motion (and commotion) since 1994, it was only in 2009 that I picked up running as an exercise as part of my effort to grasp first-hand my area of research for my $\mathrm{PhD}$ (Tan 2014). And although as an artist my running experiments have been exhibited in different contexts, including as a participatory performance at Documenta (Tan 2012), I felt that I could also make a meaningful contribution to the field as a curator. In introducing running as a sport to the arts and humanities, Bale has pioneered and advanced 'Running Studies'. Other researchers have taken on the baton to extend and broaden the discussion beyond running as an elite sport, to consider what it means to amateur runners, as a commute, how it relates to landscape, from various frameworks including geography, sociology and theatre (Lorimer 2012; Allen-Collinson and Hockey 2011; Latham 2015; Qviström 2017; Hitchings and Latham n.d.; Filmer 2016; Cook, Shaw, and Simpson 2016). But why aren't we allowed to have more fun, as a field? Could we not re-enact the child-like pleasures that can come with running? Why can't we scamper about different schools of thoughts from different fields, deliberately mix them up and engineer unexpected 
outcomes - the same way an artist creates collages and montages of disparate elements? Could we shake and mix things up, and see what happens? Theoretical positionings littered with impressive jargons that cite continental philosophy are fabulous, but where are evidences of walking or rather running, the talk? Especially since what we are talking about concerns sport, shouldn't action and practice be at the heart of this discourse? Shouldn't bold practice-led research experiments be a critical part of this inquiry? What about non-western discourses? Could a non-logocentric, 'running' approach could be interesting?

These questions led me to the philosophy of 'poetic thinking' which prizes associations, metaphoric correlations, divergence and '10,000 things' over logic, causality and singularity (Hall and Ames 1995; Miller 2003; Graham 1986), which became one of the building blocks of 'productive antagonisms' that Latham and I came up with (Latham and Tan 2016). We wanted a playful, 'ill-disciplined' interdisciplinary approach to counter the negative, tribal or self-serious tendencies of the art and academic worlds - and \#r3fest was prodictive antagonisms in action.

$<<$ Figure 3 here $>>$

Figure 3: Hampstead Heath Oak Apple Run by Simson\&Volley, 2014 (48 x 32 inches, Iron gall ink, silver and gold pigment bound in gum arabic on BFK Rives paper). This work is a map of the pathways where oak galls can be found and celebrates the beauty of the material. (Tan 2014b)

And the antagonisms were fruitful. The Guardian praised it for its 'positive atmosphere', and urged other conferences to 'take a leaf out of \#r3fests book' (Lockwood 2014). The animated curatorial approach of the festival and its expanded definition of running has since caught on. This is evidenced in programmes run by festival alumni, which themselves also feature festival alumni. They include an ESRCfunded events Running Dialogues in London (Cook 2015), a running-themed performance festival and seminar in Finland (ANTI Festival of Contemporary Art 2015), Running Wild at Fermynwoods Contemporary Art (2015) and a 6-hour run at the Festival of Grenoble in France (Cholat 2016). Two networks with the festival's alumni as members were also set up. The first is called Running Cultures Research Group with a corresponding mailing list (JISCMail n.d.). The other is the RUN! RUN! RUN! International body for Research which I founded in 2014 to run independent and 
collaborative work. I invited Latham to be Co-Director. Members, hail from Malmo, London, Cardiff and Singapore, including artists Annie Grove-White and Carali McCall (Tan 2014c).

Two years on, in 2016, I roped in Grove-White and McCall to run a second Festival, which we called the RUN! RUN! RUN! Biennale.

\section{Widening Running Studies: the RUN! RUN! RUN! Biennale 2016}

I wanted to run a second lap because I felt that the conversations have just begun. I wanted to hear and learn more, and to listen to other voices and narratives. Like other 'Studies' — Gender, Media, Walking — as a member I felt that Running Studies should not be an echo chamber of the same old tropes by the same vocal few, but a rich cacophony with new and different expressions. If the first run was a celebratory survey, a proof of concept about running's mileage as an arts and humanities discourse, and how sparks can arise from collaging different disciplines together, the second run is the 'difficult second album' (Tan 2016e). Responding to the shocking turn of events politically, the 2016 run (especially the Leeds Leg) threw a spotlight on running and its entanglement with critical issues of the day that I had found myself affected by as a woman, migrant, artist and human being, and which seemed to be strangely missing from the existing discourses from Running Studies and glossy running magazines alike. In addition, instead of expecting people to congregate at the capital, \#r3fest travelled to the regions (including the unusual location of an indoor stadium in Cardiff, Figure 4), and featured the work of regional colleagues (such as BAFTA Cymru-winner writer Catrin Kean).

$$
<<\text { Figure } 4 \text { here }>>
$$

Figure 4: Anna Brazier's performance on running as a childlike, defiant act, at \#r3fest 2016 Cardiff Leg. Photograph by Gordon Plant (Plant 2016)

Then, there was its lineup. The first run had featured the work of newcomers to the game of art, academia and running studies (such as a 23-year old undergraduate who went on to perform at the Oslo International Theatre Festival and a para athlete who responded to the Open Call who now calls herself an artist). The 2016 Biennale 
continued to showcase emerging artists, including a retired psychotherapist Anna Brazier with 30 years of work with the NHS under her belt. Furthermore, \#r3fest celebrated the efforts of the efforts of colleagues who are female (including that of members of A Mile In Her Shoes, a running charity for women affected by homelessness), older (including that of 74-year old runner and founder of Fields of Vision Doug Sandle) and disabled (including that of representatives from Headway East London, a charity for people affected by brain injury). As sociologist Monica Büscher points out,

\footnotetext{
Mobilities are embodied, involving fragile, aged, gendered, racialised bodies. Such bodies encounter other bodies, objects and the physical world multisensuously. [... ] Bodies sense and make sense of the world as they move bodily in and through it, creating discursively mediated sensescapes that signify social taste and distinction, ideology and meaning. $(2010,8)$
}

\#r3fest 2016 reminded us that there are different bodies. It spoke loudly of the richness of research, practice, action and activity on the ground that are not just heroic, privileged, territorial, logocentric, or white(-washed). It showed us how these efforts follow the well-trodden paths of, as well as depart from, the cultural canon of walking, which is often male (think Richard Long, the Situationists and Will Self), and sometimes drugged-out (think Samuel Taylor Coleridge's opium or Charles Baudelaire's hashish, against the runners' poison of choice of the runner's high). \#r3fest also illustrated how running is 'remarkable for its stunning simplicity', and the diverse demographics of the people are behind the global running boom. \#r3fest proved that not all who run and use running in their art or research are what I term MAMIR or middleaged men in running-shorts, or the MAMIRA, the middle-aged men in running-shorts in academia, both of whom are close cousins of the MAMIL or middle-aged man in lycra.

As a MAWIRA, or middle-aged woman in running-shorts in academia, myself, let me now run through a few examples of the innovative experiments shared at \#r3fest.

\section{Cardiff Leg: Live art on running and the body}

The Cardiff Leg was subtitled How does running (dis)connect people with the body? 
Through an evening of live art, readings and discussions at the National Indoor Athletics Centre of Cardiff School of Sport, participants discussed the ways in which running draws out the possibilities as well as limitations of the human body.

How running relates to the ageing, female body was foregrounded in 3 presentations: a performance by Anna Brazier, the retired psychotherapist, a short film Breath / Mind / Muscle by co-curator Annie Grove-White, who began running in her 50 's to counter the onset of osteoporosis which had affected her mother, as well as a reading by writer Catrin Kean of her new memoir on her marathon-running in different parts of the world. As co-curator Carali McCall dashed back and forth in front of the audience, she held and counted her breath, each time with shorter recovery times that she had imposed for herself. In the ensuing discussions led by Aberystwyth University's Andrew Filmer of and myself, the topics of injury, pain and the pleasures of running were covered - all this appropriately taking place inside the massage room within the Centre, overlooked by models of human skeletons and charts about the human anatomy and ways to heal it back to health.

$<<$ Figure 5 here $>>$

Figure 5: Eddie Ladd and her performance-lecture. Photograph by Phil Martin.(Tan 2016c)

The standout act for the evening was a performance-lecture by award-winning international performance maker Eddie Ladd (Figure 5). This drew on an acclaimed dance-theatre piece that she created in 2010. Entitled Ras Goffa Bobby Sands/The Bobby Sands Memorial Race, it was a portrait of the famed hunger striker of the Irish Republican Army Bobby Sands - through running. For the performance in the theatres, she ran for 50 minutes on stage on a specially-built oversized treadmill (Ladd n.d.). While Ladd used an ordinary treadmill in the Health and Exercise Research Centre for her re-enactment, how she manipulated the machine and her body was nothing short of spellbinding. Through the 30-minute act, the Welsh artist enacted how Bobby Sands smokes a cigarette, sleeps, and undergoes physical and mental deterioration as the hunger strike progresses - all the while running on the treadmill. At times she seemed unable to catch up with the speeding machine; at others she sedated and tamed it. Requiring and revealing strength and stamina as it did vulnerability and despair, Eddie's 
piece powerfully used running - and running on a treadmill - as a metaphor for the precarious and paradoxical tensions between life and death, between end (reaching your dream) and the means to the end (pain, sacrifice). In so doing, not only did she pay tribute to a historical figure who was also an amateur runner, but the everyman in their daily grind. The performance also conjured our heritage as persistence hunters, when running was a tool of survival - only that in Sands' case, ironically, he had deliberately rejected food to get his point across. We run and carry on running, because we dream far ahead and imagine a better outcome - even if it means pushing our body to its extreme and running it down.

\section{London Leg: film screening (and popup tour) on running and the city}

Zooming out, the 'London Leg' of \#r3fest asked: how does running (dis)connect people with the city?

The evening began with a popup running tour of the changing landscapes of King's Cross with the aim to 'wake up our minds and bodies' ahead of the film screening (Tan and Cole 2016). The tour was conceived and run by personal trainer and alternative tour guide Simon Cole from the acclaimed Hackney Tours. With the slogan of 'alternative, independent, East London', Hackney Tour's unusual repertoire includes 'Subversive Stoke Newington' and 'Action Women Run! \#Runtivism' (Cole 2017). Cole's proposal of running as a means to understand, feel a sense of ownership of and express one's autonomy in the city was echoed in my film shown at the film screening, entitled Hand-In-Hand (2016a).

Other films explored running as not only subject matter but aesthetic approach. Jenny Baines' Untitled (Rooftop) and Joe King's Mobius Strip were depictions of the city. Their Structuralist approach to the editing conjured the rhythms and playfulness of running. They also made me think of why 'moving images' are thus called, because they are still images that appear to move due to the human eye's ability to 'join up' the images via the phenomena of the persistence of vision - and aren't early persistence hunters and modern-day amateur marathon runner linked by a kind of "persistence of vision'? Then, there was Musquiqui Chihying's The Jog, which parodied the selfseriousness of runners and chore of running, with the Taiwanese artist performing a run on a supermarket's conveyer belt. This created a dialogue with Veronique Chance's 
rightly clinical tone in her In the Absence of Running - which was a documentation of her knee operation for her injury from running, which in turn spoke to Annie GroveWhite's Breath / Mind / Muscle, screened here again (Figure 6).

\section{$<<$ Figure 6 here $>>$}

Figure 6: Still from Breath / Mind / Muscle, Annie Grove-White (2014).

\section{Carali McCall's Extract, from Work no. 4 (Running/Restraint) Back Hill similarly} explored the abilities and limitations of the body, and how this body interacts with the place in which it lives, breathes and moves (2013). In a review of \#r3fest, David Hindley reminds us of the words of illustrator Leanne Shapton, who observes that 'artistic discipline and athletic discipline are kissing cousins, they require the same thing, an unspecial practice...' (2016). It is obvious from McCall's film, as it is from Ladd's performance, how work that use running may require a level of athleticism, endurance and, once again, persistence. These are features that run deep in the tradition of endurance or durational art (think for instance Chris Burden's Five-Day Locker Piece and Teh-Ching Hsieh's One Year Performances), and which Gregg Whelan's curated 2015 programme at the ANTI Festival highlighted through its seminar The Art of Endurance and Tristram Meecham's Fun Run, in which he ran a full marathon - 26 miles - in front of a live audience in Kuopio, Finland (2015). McCall's chosen mise-enscene in a street in London. Her body is tethered to an elastic band, one end of which is attached to a bollard. McCall runs back and forth repeatedly in what seems like a 'Sisyphean task' (Tainio 2016), until the elastic band snaps. McCall conceptualises running is a form of drawing (2014). By extension, when she runs in the city, the city becomes her canvas for her body to draw on, and to wrestle with - literally so.

\footnotetext{
$<<$ Figure 7 here $>>$
}

Figure 7: A Mile In Her Shoes. Photograph by Damian Walker. (2016)

The discussion that followed wrestled with the ways in which the running body navigates and negotiates the urban space. Led by artist Jo Volley and geographer Alan Latham, respondents include writer Simon Freeman (Like the Wind), and friends from charities A Mile in her Shoes (Figure 7) and Headway East London. A metropolis like London presents challenges for anyone; those who are homeless or have a neurological 
difference run into additional barriers in how they are seen, and how they see. It is through learning about the lived experiences of these colleagues, and how they use running as a means to 'find their feet' (website 2013) and give them a different identity and label, and reminds the MAMIRs, MAMIRAs or MAWIRAs amongst us that there are different bodies, and they sense and make sense of the world differently, and what they know can enrich what we thought we knew.

\section{Leeds Leg: seminar on running and borders}

And gender does come into play in the consideration of how bodies move about - or not. Today, with Trump, Brexit and a rise in protectionist, isolationist policies and behaviours, we are once again inhabiting an era in which walls are being erected, boundaries hardened and our movement as runners, migrants, travellers and women restricted, and minds closed as we fear the other. For those who cannot run away from conflict areas, staying alive can be tough, let alone running, outdoors - particularly for those who are not male. Running thus is not only something that can be positive for your physical and mental wellbeing, but a demonstration — literally and metaphorically-speaking — of autonomy and defiance.

$<<$ Figure 8 here $>>$

Figure 8: Free to Run (2016)

These were the territories of the Leeds Leg, which was subtitled How does running (dis)connect people with borders? This was a seminar held at Leeds College of Art. Its starting point was Jun Nguyen-Hatsushiba's seminal performance Breathing is Free: 12,756.3 (ongoing since 2007), which is the artist's attempt to experience world refugee crisis by running the diameter of the earth, $12,756.3 \mathrm{~km}$. Chaired by principal curator Sarah Brown (Leeds Art Gallery), the headline act was a Skype conversation with UN human-rights lawyer Stephanie Case, president of Free To Run, a running group for women in Afghanistan (Figure 8). Her story, as Hindley writes, is 'one of empowerment and transformation, using running, fitness and outdoor adventure programmes as an avenue to freedom, to foster social networks of support, and to help shift the perception of gender roles in war-torn societies where women and girls are 
disproportionately affected by conflict' (2016). Her narrative was set in an interesting tension with that presented by Debbie Lisle, a Reader in International Relations at Queen's University Belfast. Lisle presented a scathing critique of culture and industries generated by the Marathon Des Sables. This is an iconic race consisting of running for seven days across the Sahara desert that draws hundreds of ultra-marathon runners annually. For Lisle, this represents 'established colonial asymmetries are recast in a neoliberal context' as runners 'test their resilience, endurance and strength' against an "extreme" Saharan landscape'. The 'central conceit' of the marathon - that 'superior Western fitness regimes and technologies will dominate the race' — is 'inverted' by the overwhelming success of a handful of Moroccan runners year after year. Set side-byside with that of Case's, Lisle's argument thus provoked a reflection on the politics of different bodies — white/non-white, saviour/ victim, colonial/colonised, researcher/'subject'. Also on running and the international stage was Certainly the Toughest Ultramarathon of Your Life, a colourful drawing that I created as a response to the (anti-) migrant crisis. The work aimed to tease out the irony between the gruelling journeys that migrants undertake to seek asylum, and the pursuit made by the 'escapees' and 'weekend warriors' of Europe seeking gruelling (and exorbitant) endurance challenges in the name of fitness, adventure and/or self-fulfilment (2016b).

It is not just geopolitical borders but disciplinary, artistic and personal to consider, and the role of running in this mix. This is where the efforts of Doug Sandle comes in. The founding Chair of Fields of Vision, who is still a runner at the age of 74, provided 'an impassioned defence for marrying the potentially unlikely pairing of the artist and the athlete' through a set of examples from both the arts and sport to illustrate the arts' potential to 'celebrate, encapsulate and express sports practice and culture' (Hindley 2016). Fields of Vision member artist Lisa Stansbie used the work of Dutch artist and triathlete Guido Van Der Werve, to highlight the common grounds shared by the two disciplines, including physical effort, solitude, repetition, and boredom. Carrying on with the theme of the importance to learn from other disciplines, as well as to 'float' more ideas around, the Leeds Leg closed not with running but swimming. Drawing on her (auto)ethnographic study, sociologist Karen Throsby uses endurance swimming 'as a conduit for thinking about mind-body boundaries (reflected in the 'mind over matter' rhetoric championed by the marathon swimming community) as well as the freedoms and privileges the sport demands, alluding to the resource-greedy nature 
of the leisure pursuit, as well the mobility and financial capital necessary to compete' as she swims across borders (Hindley 2016). Amidst this discomforting analysis, Throsby also shares the pleasures of engaging her body in the endurance sport.

\section{What next? Dreaming far ahead}

Where do we go from here? [...] amidst the potential to identify aspects of common ground, the assorted line-up (or in Kai's words 'mix-and-mismatch programming') invariably leads to incongruities and divergent paths. By drawing upon and navigating such diverse perspectives, the resultant challenge and blurring of these distinctions will hopefully provide further insights into the ways people understand the pursuit of running in their own lives. - Hindley 2016

Works of art that have continued to intrigue are not those that provide the answers, but those that problematise, interrogate, and provoke. Covering the RUN! RUN! RUN! Biennale's origins and curatorial framework, the paper has raised philosophical questions about synergies between arts and sport, as well as suggested a new way of considering how arts and sports can be organised, considered and presented. For Matti Tainio, for all its 'disconnectedness', \#r3fest presented

\footnotetext{
[...] a path the participants were willing to travel together, but there wasn't an established way to do it - yet. The various interests and agendas still need time to grow closer to each other. We need to develop this discourse further in order to be able to really understand and articulate the change that is taking place. For this, we should arrange more meetings and take time to talk about our art and our research. - Tainio 2016
}

It is not my intention of to spell out an optimal path for the arts and running. While it was created with the goal of filling in what I have perceived as gaps in the field, the \#r3fest is itself deliberately incomplete, sketchy, filled with ellipsis and its own gaps that it invites you to fill and dig further. By running though the curatorial framework of the $\#$ r3fest, which creates spaces of interdisciplinary productive antagonisms, and by shining a spotlight at 2016 run on the innovative efforts by colleagues that are hitherto underrepresented in dominant discourses in the so-called 'Running Studies', my aim has been to help to widen the discourse, invite curators, artists and academics to consider, 
curate and create yet other experiments that activate running as creative material, metaphor and methodology, and challenge our existing assumptions in the arts.

Particularly amidst an increasingly unstable and unwell reality marked by fear, division, anxiety and funding cuts today, I argue that the roles of the arts, sport and their hybrids as spaces of distraction, reflection, connection and collaboration are more important than ever. This is the challenge, and opportunity, for academics and artists next.

I would like to thank colleagues David Hindley, Matti Tainio, Carali McCall, Annie GroveWhite, Alan Latham, Andrew Filmer, and all the participants and audiences of the RUN! RUN! RUN! Biennale 2016 for their inspiration and support for \#r3fest, which has given me much food for thought, some of which I have attempted to reflect in this paper. \#r3fest 2016 was sponsored by Leeds College of Art, and the site sponsors were University College London's Department of Geography and Cardiff School of Sport. In addition, I would like to thank Free To Run, A Mile In Her Shoes and Jo Volley for permission to use their images here.

\section{References}

Allen-Collinson, Jacquelyn, and John Hockey. 2011. 'Feeling the Way: Notes toward a Haptic Phenomenology of Scuba Diving and Distance Running'. International Review for the Sociology of Sport 46 (3):330-45.

A Mile in Her Shoes. 2016. A-Mile-in-Her-Shoes. http://www.amileinhershoes.org.uk. ANTI Festival of Contemporary Art. 2015. International Seminar - Art of Endurance Seminar. https://vimeo.com/145036633.

Bale, John. 2004. Running Cultures: Racing in Time and Space. Psychology Press.

Bartlett School of Architecture. 2016. 'MAAH_Course Information Sheet_template'. Bartlett School of Architecture. 2016.

https://webcache.googleusercontent.com/search?q=cache:bos7LNIcNnkJ:https:// www.bartlett.ucl.ac.uk/architecture/programmes/postgraduate/ma-architecturalhistory/documents/MAAH_Course_Information_Sheet_2016_16112.pdf $+\& \mathrm{~cd}=$ $3 \& \mathrm{hl}=\mathrm{en} \& \mathrm{ct}=\mathrm{clnk} \& \mathrm{gl}=\mathrm{uk} \& \mathrm{client}=$ safari.

Bramble, Dennis M., and Daniel E. Lieberman. 2004. 'Endurance Running and the Evolution of Homo'. Nature 432 (7015):345-52. https://doi.org/10.1038/nature03052.

Büscher, Monika, ed. 2010. Mobile Methods. 1 edition. Abingdon, Oxon ; New York, NY: Routledge.

Chen, Ingfei. 2006. 'Human Evolution: Born To Run'. DISCOVER Magazine, May 2006. http://discovermagazine.com/2006/may/tramps-like-us.

Cholat, Florent. 2016. Les 6 Heures de Grenoble. http://kaisyngtan.com/portfolio/handinhand/.

Cole, Simon. 2017. 'Hackney Tours - Alternative Experience Walks, Radical Running Tours \& Brilliant Bike Rides in the Most Exciting Part of London'. 2017. https://hackneytours.com/.

Cook, Simon. 2015. 'Running Dialogues Summary'. 2015. http://www.freestak.com/wp-content/uploads/2015/04/Running-DialoguesSeminars-Summary.pdf.

Cook, Simon, Jon Shaw, and Paul Simpson. 2016. 'Running Order: Urban Public Space, Everyday Citizenship and Sporting Subjectivities'. In Critical 
Geographies of Sport: Space, Power and Sport in Global Perspective, edited by Natalie Koch, 157-72. Routledge.

Creed, Martin. 2008. Work No. 850. http://www.martincreed.com/site/works/work-no850.

Dietrich, A, and W McDaniel. 2004. 'Endocannabinoids and Exercise'. British Journal of Sports Medicine 38 (5):536-41. https://doi.org/10.1136/bjsm.2004.011718.

Fermynwoods Contemporary Art. 2015. 'Wild Projects \#5'. Fermynwoods Contemporary Art. 2015. http://www.fermynwoods.co.uk/archive/workshopstalksevents/wildprojects/wild-projects-5/.

Filmer, Andrew. 2016. 'Motion Capture'. 2016. https://www.academia.edu/27066641/Motion_Capture.

Free To Run. 2016. Our Mission. http://www.freetorun.org/our-mission/.

Glasgow School of Art. 2011. 'Sculpture Year 3 Studio Course Specification'. 2012 2011. http://webcache.googleusercontent.com/search?q=cache:RE_ui_vE5UJ:www.gsa.ac.uk/media/218366/Sculp $\% 2520 \mathrm{Yr} \% 25203, \overline{0} \% 2520$ term $\%$ $25203, \% 2520$ Studio\%2520-

$\% 2520 \mathrm{BA} \% 2520$ (Hons)\%2520Fine\%2520Art.pdf $+\& \mathrm{~cd}=5 \& \mathrm{hl}=\mathrm{en} \& \mathrm{ct}=\mathrm{clnk} \& \mathrm{gl}$ $=$ uk\&client $=$ firefox-b-ab.

Godwin, Mike. 2005. 'Neal Stephenson's Past,Present, and Future - Reason Magazine'. Reason.com. 2005. http://reason.com/archives/2005/02/01/neal-stephensonspastpresent-a/print.

Graham, A. C. 1986. Yin-Yang and the Nature of Correlative Thinking. Institute of East Asian Studies.

Hall, David L., and Roger T. Ames. 1995. Anticipating China: Thinking Through the Narratives of Chinese and Western Culture. State University of New York Press.

Heinrich, Bernd. 2002. Why We Run: A Natural History. Reprint. Harper Perennial.

Hind, John. 2014. 'Lager, Red Bull and Swimming 40 Lengths: A Tracey Emin Weekend'. The Guardian, 17 August 2014, sec. Art and design. http://www.theguardian.com/artanddesign/2014/aug/17/tracey-emin-weekendlager-red-bull-swimming.

Hindley, David. 2016. ‘\#r3fest Leeds Leg Review’. RUN RUN RUN Biennale (blog). 3 December 2016. http://kaisyngtan.com/r3fest/leeds-leg-review/.

Hitchings, Russell, and Alan Latham. n.d. 'How “social” Is Recreational Running? Findings from a Qualitative Study in London and Implications for Public Health Promotion'. Health \& Place. Accessed 8 January 2017. https://doi.org/10.1016/j.healthplace.2016.10.003.

JISCMail. n.d. 'JISCMail - RUNNING-CULTURES List at WWW.JISCMAIL.AC.UK'. Accessed 20 August 2017. https://www.jiscmail.ac.uk/cgi-bin/webadmin?A0=RUNNING-CULTURES.

Ladd, Eddie. n.d. Ras Goffa Bobby Sands/the Bobby Sands Memorial Race. Accessed 13 May 2017. http://www.eddieladd.com/the-Bobby-Sands-memorial-race.html.

Latham, Alan. 2015. 'The History of a Habit: Jogging as a Palliative to Sedentariness in 1960s America'. Cultural Geographies 22 (I):103-26. https://doi.org/10.1177/1474474013491927.

Latham, Alan, and Kai Syng Tan. 2016. 'Running into Each Other: Run! Run! Run! A Festival and a Collaboration'. Cultural Geographies, Cultural Geographies, . http://cgj.sagepub.com/. 
Leeds College of Art. 2014. 'Research Fellows Runs UCL Art Museum Commission | Leeds College of Art'. November 2014. http://www.leeds-art.ac.uk/newsevents/news/2014/11/10/research-fellows-runs-ucl-art-museum-commission/.

Liebenberg, Louis. 2008. 'The Relevance of Persistence Hunting to Human Evolution'. Journal of Human Evolution 55 (6):1156-59. https://doi.org/10.1016/j.jhevol.2008.07.004.

Lockwood, Alex. 2014. 'Running and Academia: The Intellectual Aspect of Pounding the Pavements', 30 June 2014. https://www.theguardian.com/lifeandstyle/therunning-blog/2014/jun/30/running-academia-intellectual-aspect-poundingpavements.

Lorimer, Hayden. 2012. 'Surfaces and Slopes'. Performance Research 17 (2):83-86. https://doi.org/10.1080/13528165.2012.671080.

Marathon Guide. 2012. 'MarathonGuide.com - International Marathons Races Directory and Schedule'. 2012. http://www.marathonguide.com/races/races.cfm?place=intl.

McCall, Carali. 2013. 'Work No. 4 (Restraint Running) Back Hill, 2013 - Edited Version on Vimeo'. 2013. https://vimeo.com/115101499. 2014. 'A Line Is a Brea(d)thless Length: Introducing the Physical Act of Running as a Form of Drawing'. Phd, University of the Arts London. http://ualresearchonline.arts.ac.uk/6511/.

Miller, James. 2003. Daoism: A Short Introduction. Oneworld Publications.

Newsholme, Eric, and Tony Leech. 1983. Runner: Energy and Endurance. Walter L Meagher.

Oates, Carol Joyce. 1999. 'Writers on Writing'. The New York Times, 1999. http://www.scribd.com/doc/7391268/Writers-on-Writing.

Palestine Marathon. 2013. 'Palestine Marathon - Right To Movement'. 2013. http://righttomovement.com/.

Perry, Grayson. 2015. "“Cycling Is the Perfect Sport for Transvestites”". The Guardian, 2 May 2015, sec. Life and style. http://www.theguardian.com/lifeandstyle/2015/may/02/cycling-is-the-perfectsport-for-transvestites.

Plant, Gordon. 2016. 'RUN! RUN! RUN!' 2016. http://www.gordons.photos/runrunrun.

Qviström, Mattias. 2017. 'Competing Geographies of Recreational Running: The Case of the "jogging Wave" in Sweden in the Late 1970s'. Health \& Place 46 (July):351-57. https://doi.org/10.1016/j.healthplace.2016.12.002.

Searle, Adrian. 2017. 'Chris Ofili: Weaving Magic Review - a Totally Tropical Tapestry'. The Guardian, 25 April 2017, sec. Art and design. http://www.theguardian.com/artanddesign/2017/apr/25/chris-ofili-weavingmagic-review-a-totally-tropical-tapestry.

Sillitoe, Alan. 2010. The Loneliness of the Long-Distance Runner. 1st ed. Vintage.

Tainio, Matti. 2016. '\#r3fest London Leg Review'. RUN RUN RUN Biennale (blog). 13 December 2016. http://kaisyngtan.com/r3fest/london-leg-review/.

Tan, Kai Syng. 2012. 'Kaidie Passes on (some Of) Her Final Messages in an Interactive Performance of a "running Discourse" at dOCUMENTA (13), Kassel, Germany'. Kaidie's 1000-Day Trans-Run: 12.12.2009 - 09.09.2012 (blog). 8 September 2012. http://3rdlifekaidie.com/2012/09/kaidie-documentakaisyngtan/. . 2014a. 'THE PHYSICAL AND POETIC PROCESSES OF RUNNING: A Practice-Related Fine Art Discourse About A Playful Way To Transform Your 
World Today'. University College London.

http://discovery.ucl.ac.uk/1420270/1/Tan_Kai_Syng_Thesis_Redacted.pdf. . 2014b. 'A FAB FIRST RUN 2014'. RUN RUN RUN Biennale (blog). 28 June 2014. http://kaisyngtan.com/r3fest/our-first-run/.

. 2014c. 'RUN BY'. RUN!RUN!RUN! International Body for Research (blog). 1 October 2014. http://kaisyngtan.com/portfolio/run-by/.

. 2015. 'PechaKucha 20x20 - RUN! RUN! RUN!' PechaKucha 20x20. 2015. http://www.pechakucha.org/cities/kuopio/presentations/run-run-run.

2016a. 'Run Run Run. Hand in Hand. Run into and Run with One Another. on Vimeo'. 2016. https://vimeo.com/172991771.

- 2016b. 'Tough Ultramarathons and Life on the Run'. Berghahn Journals Transfers Transfers. http://journals.berghahnbooks.com/transfers.

2016c. 'RUN! RUN! RUN! BIennale 2016 CURATORIAL FRAMEWORK'. RUN RUN RUN Biennale (blog). 19 October 2016.

$\mathrm{http}: / /$ kaisyngtan.com/r3fest/2016-curatorial-statement/. . 2016d. RUN RUN RUN Biennale Flyer (overview).

$\mathrm{http}: / /$ kaisyngtan.com/r3fest/.

- 2016e. 'What Has Running Got to Do with Our Divided World? - RSA'. Royal Society of the Arts Blog (blog). 16 November 2016.

https://www.thersa.org/discover/publications-and-articles/rsa-

blogs/2016/11/what-has-running--got-to-do-with-the-migrant-crisis.

Tan, Kai Syng, and Simon Cole. 2016. LONDON Leg: Pop-up Warm-up Event. http://kaisyngtan.com/r3fest/2016-london/.

Tykwer, Tom. 1999. Run Lola Run. Sony Pictures.

Virgin Money London Marathon. 2017. '06 The Mass Event'. http://londonmarathon.s3.amazonaws.com/vmlm2014/live/uploads/cms_page_media/206/6. \%20The\%20Mass\%20Event.pdf.

Wheatley, George. 2015. A Visit (In 1831) to Jeremy Bentham. University College London. http://discovery.ucl.ac.uk/1462164/1/wheatley.pdf.

Whelan, Gregg. 2017. 'Run It By Me', 3 March 2017. https://www.pressreader.com/uk/runners-worlduk/20170303/281642484901246.

Wray, Katie. 2014. 'Are We Becoming a Nation of Runners?' $B B C, 30$ November 2014, sec. England. http://www.bbc.co.uk/news/uk-england-30036800. 